\title{
Simulation Study of Confounder Selection Procedures using the Hoffman's Collapsibility Test
}

\author{
Shiro Tanaka* \\ Department of Clinical Biostatistics, Kyoto University, Japan
}

Submission: May 29, 2017; Published: July 27, 2017

*Corresponding author: Shiro Tanaka, Department of Clinical Biostatistics, Graduate School of Medicine, Kyoto University, Kyoto, Japan, Email: gogosata@gmail.com

Abbreviations: AA: Always Adjusted; AO: Always Omitted; CSP: Confounder Selection Procedure; CT: Collapsibility Test; LT: Log-Rank Test; RMSE: Root Mean Square Error

\section{Introduction}

Hoffman et al. proposed a convenient collapsibility test in Cox regression [1]. Collapsibility tests have been considered as an effective way to select confounders to be included in multiplicative rate models [2]. However, it is not reasonable to expect that the performance of a confounder-selection procedure (CSP) using the Hoffman's test is as shown in [2]. First, unlike multiplicative rate models, the regression coefficient of exposure in Cox regression is not collapsible even if the covariate is independent of exposure [3]. Second, impact of a CSP would be different when confounders are adjusted by propensity-score [4]. Although Hoffman et al. did not recommend applying their test to confounder selection problems, these issues should be addressed.

\section{Simulation Settings}

In this simulation study, we randomly generated 1000 data sets from a hypothetical cohort study of $\mathrm{N}=500$ and 5000 . The data sets included an observed survival time $\mathrm{T}$, a censoring indicator $\delta$, a binary exposure $\mathrm{X}=-1 / 2,1 / 2$, a known confounder $\mathrm{Z} 1$, and a potential confounder Z2, which were generated in four steps. First, $\mathrm{Z}$ follows a multivariate normal with mean zero, unit variance, and correlation $\mathrm{r}=0.5$.Second, $\mathrm{X}$ given $\mathrm{Z}$ follows a Bernoulli distribution with a conditional probability given by $\operatorname{logit}\{\operatorname{Pr}(\mathrm{X}=1 / 2 \mid \mathrm{Z})\}=\log (0.5)+\log (2) \mathrm{Z} 1+\gamma \mathrm{Z} 2$. Third, the true survival time $\mathrm{T}^{*}$ given $\mathrm{X}$ and $\mathrm{Z}$ follows an exponential distribution with a hazard $\lambda=0.1 \exp (\beta X+\log (2) Z 1+\alpha Z 2)$. Finally, $\mathrm{T}=\min \left(\mathrm{T}^{*}, \eta \mathrm{U}\right)$, where $\mathrm{U}$ follows a uniform distribution and $\eta$ was specified so that the censoring probability is 0.8.Table 1 presents results from the following combinations of parameters: $\{\exp (\gamma), \exp (\alpha), \exp (\beta)\}=(1,1,3),(2,1,3),(1,2,3)$,
$(2,2,3)$. After data generation, we estimated $\beta$ by fitting four Cox regression models; $\lambda(t)=\lambda 0(t) \exp (\beta X+\alpha 1 Z 1+\alpha 2 Z 2), \lambda(t)=\lambda 0(t)$ $\exp (\beta \mathrm{X}+\alpha 1 \mathrm{Z1}), \quad \lambda(\mathrm{t})=\lambda 0 \mathrm{a}(\mathrm{t}) \exp (\beta \mathrm{X}), \quad$ and $\lambda(\mathrm{t})=\lambda 0 \mathrm{c}(\mathrm{t}) \exp (\beta \mathrm{X})$, where $\lambda 0 \mathrm{a}(\mathrm{t})$ and $\lambda 0 \mathrm{c}(\mathrm{t})$ are stratified baseline hazard functions according to quintile of propensity-scores estimated by logistic regression with a covariate vector $\mathrm{Z}=(\mathrm{Z} 1, \mathrm{Z} 2)$ or $\mathrm{Z} 2$, respectively. These models were selected by four CSPs: Always Adjusted (AA), Always Omitted (AO), the Hoffman's Collapsibility Test (CT) [1], and Log-rank Test (LT). In the LT-procedure, Z2 is omitted if Z2 correlated with $\mathrm{T}$ significantly in Cox regression with a covariate vector Z. Significance levels were set as 0.2 . The performance was evaluated in terms of bias and root MSE(RMSE) in $\beta:$ Bias $=1000^{-1} \sum_{i=1}^{1000}\left(\hat{\beta}_{i}-\bar{\beta}_{\mathrm{AA}}\right)$ and

$$
R M S E=\left\{\sqrt{1 / 1000 \sum_{i=1}^{1000}\left(\hat{\beta}_{i}-\bar{\beta}_{A A}\right)^{2}}-R M S E_{A A}\right\} / R M S E_{A A}
$$

where $\beta^{-}$aA and RMSE $E_{A A}$ are the simulated mean and RMSE from the AA-procedure. A negative value in RMSE indicates improvement over the AA-procedure.

\section{Simulation Results}

In Table 1 , biases in the A0-procedure were present in $(1,2,3),(2,2,1)$ and $(2,2,3)$ in regression adjustment, while $\beta$ was not collapsible numerically only in $(2,2,1)$ and $(2,2,3)$ in propensity-score stratification. As expected, the CT-procedure frequently included $\mathrm{Z} 2$ when $\beta$ is not collapsible even if $\mathrm{Z} 2$ is not a confounder ( $41 \%$ in $\mathrm{N}=500,95 \%$ in $\mathrm{N}=5000$ ). Therefore, the Hoffman's test is a valid collapsibility test but cannot exclude a non-confounder if it correlates with T. Further, power of the CTprocedure to detect a confounder was consistently lower than 
the LT-procedure when $\mathrm{N}=500$. Notably, in scenarios $(1,2,1)$ and $(1,2,3)$ and when propensity-score stratification was used, we see result similar to [4]; the AA-procedure improved RMSE by 2.4 to $4.2 \%$ from the AO-procedure, which always specified the correct exposure model but missed a non-confounder which correlates with T. As noted above, the CT-procedure failed to include Z2 in $(1,2,1)$ and $(1,2,3)$, yielding lower RMSE than the
LT-procedure ( 0 to $0.7 \%$ ). We also performed sensitivity analyses and observed qualitatively the same pattern. The efficiency gain in propensity-score analysis was high when prevalence of exposure or correlation across confounder was low, but very small when $\mathrm{Z} 1$ is high-dimensional, e.g. 20 variables. In conclusion, the Hoffman's test yields a less efficient estimate of exposure in confounder-selection problem (Table 1).

Table 1: Root Mean Squared Error Relative to the Always Adjusted Procedure by Different Confounder Selection Procedures and Adjustment Methods

\begin{tabular}{|c|c|c|c|c|c|c|c|c|c|c|c|c|}
\hline \multicolumn{7}{|c|}{ Adjustment as a Covariate in Cox Regression } & \multicolumn{6}{|c|}{ Adjustment by Propensity-Score Stratified Cox Regression } \\
\hline & \multicolumn{2}{|c|}{ Always Omitted } & \multicolumn{2}{|c|}{ Collapsibility Test } & \multicolumn{2}{|c|}{ Log-Rank Test } & \multicolumn{2}{|c|}{ Always Omitted } & \multicolumn{2}{|c|}{ Collapsibility Test } & \multicolumn{2}{|c|}{ Log-Rank Test } \\
\hline Parameter & Bias & RMSE & & (\%omitted) & RMSE & (\%omitted) & Bias & RMSE & RMSE & (\%omitted) & RMSE & (\%omitted) \\
\hline \multicolumn{13}{|l|}{$N=500$} \\
\hline$(1,1,1)$ & 0 & $-0.20 \%$ & $-0.10 \%$ & $-98 \%$ & $0.00 \%$ & $-78 \%$ & 0 & $0.30 \%$ & $0.50 \%$ & $-86 \%$ & $0.50 \%$ & $-78 \%$ \\
\hline$(2,1,1)$ & 0 & $-2.30 \%$ & $-1.20 \%$ & $-81 \%$ & $-1.10 \%$ & $-78 \%$ & 0 & $-0.50 \%$ & $-0.40 \%$ & $-85 \%$ & $-0.20 \%$ & $-78 \%$ \\
\hline$(1,2,1)$ & -0.01 & $1.10 \%$ & $0.50 \%$ & $-80 \%$ & $0.00 \%$ & $0 \%$ & 0 & $3.50 \%$ & $0.60 \%$ & $-68 \%$ & $0.00 \%$ & $0 \%$ \\
\hline$(2,2,1)$ & 0.32 & $70.90 \%$ & $0.10 \%$ & $0 \%$ & $0.00 \%$ & $0 \%$ & 0.26 & $56.40 \%$ & $2.10 \%$ & $-8 \%$ & $0.00 \%$ & $0 \%$ \\
\hline$(1,1,3)$ & 0 & $0.00 \%$ & $-0.10 \%$ & $-98 \%$ & $0.10 \%$ & $-78 \%$ & 0 & $0.20 \%$ & $0.20 \%$ & $-87 \%$ & $0.50 \%$ & $-78 \%$ \\
\hline$(2,1,3)$ & 0 & $-2.60 \%$ & $-1.10 \%$ & $-83 \%$ & $-1.30 \%$ & $-80 \%$ & 0.02 & $-1.10 \%$ & $-1.30 \%$ & $-85 \%$ & $0.00 \%$ & $-80 \%$ \\
\hline$(1,2,3)$ & -0.09 & $9.00 \%$ & $1.40 \%$ & $-59 \%$ & $0.00 \%$ & $0 \%$ & 0 & $2.30 \%$ & $0.70 \%$ & $-79 \%$ & $0.00 \%$ & $0 \%$ \\
\hline$(2,2,3)$ & 0.25 & $39.70 \%$ & $0.70 \%$ & $-4 \%$ & $0.00 \%$ & $0 \%$ & 0.22 & $34.90 \%$ & $2.20 \%$ & $-14 \%$ & $0.00 \%$ & $0 \%$ \\
\hline \multicolumn{13}{|l|}{$\mathrm{N}=5000$} \\
\hline$(1,1,1)$ & 0 & $0.00 \%$ & $0.00 \%$ & $-99 \%$ & $0.00 \%$ & $-82 \%$ & 0 & $-0.20 \%$ & $0.20 \%$ & $-81 \%$ & $-0.20 \%$ & $-82 \%$ \\
\hline$(2,1,1)$ & 0 & $-2.40 \%$ & $-2.10 \%$ & $-81 \%$ & $-2.00 \%$ & $-81 \%$ & 0.01 & $0.80 \%$ & $-1.00 \%$ & $-84 \%$ & $0.80 \%$ & $-81 \%$ \\
\hline$(1,2,1)$ & 0 & $2.40 \%$ & $0.40 \%$ & $-78 \%$ & $0.00 \%$ & $0 \%$ & 0 & $4.20 \%$ & $0.00 \%$ & $-37 \%$ & $0.00 \%$ & $0 \%$ \\
\hline$(2,2,1)$ & 0.32 & $350.00 \%$ & $0.00 \%$ & $0 \%$ & $0.00 \%$ & $0 \%$ & 0.26 & $289.10 \%$ & $0.00 \%$ & $0 \%$ & $0.00 \%$ & $0 \%$ \\
\hline$(1,1,3)$ & 0 & $-0.10 \%$ & $-0.10 \%$ & $-99 \%$ & $-0.10 \%$ & $-81 \%$ & 0 & $-0.40 \%$ & $-0.10 \%$ & $-82 \%$ & $-0.30 \%$ & $-81 \%$ \\
\hline$(2,1,3)$ & 0 & $-2.30 \%$ & $-1.40 \%$ & $-82 \%$ & $-1.40 \%$ & $-82 \%$ & 0.02 & $2.80 \%$ & $1.00 \%$ & $-63 \%$ & $2.30 \%$ & $-82 \%$ \\
\hline$(1,2,3)$ & -0.08 & $52.30 \%$ & $0.80 \%$ & $-5 \%$ & $0.00 \%$ & $0 \%$ & 0 & $2.40 \%$ & $0.50 \%$ & $-65 \%$ & $0.00 \%$ & $0 \%$ \\
\hline$(2,2,3)$ & 0.25 & $219.30 \%$ & $0.00 \%$ & $0 \%$ & $0.00 \%$ & $0 \%$ & 0.22 & $189.20 \%$ & $0.00 \%$ & $0 \%$ & $0.00 \%$ & $0 \%$ \\
\hline
\end{tabular}

\section{References}

1. Hoffmann K, Pischon T, Schulz M, Schulze MB, Ray J, et al. (2008) Statistical test for the equality of differently adjusted incidence rate ratios. Am J Epidemiol 167(5): 517-522.

2. Maldonado G, Greenland S (1993) Simulation study of confounder selection strategies. Am J Epidemiol138: 923-936.
3. Greenland S, Robins JM, Pearl J (1999) Confounding and collapsibility incausal inference. Statist Sci 14(1): 29-46.

4. Brookhart MA, Schneeweiss S, Rothman KJ, Glynn RJ, Avorn J, et al. (2006) Variable selection for propensity score models. Am J Epidemiol 163(12):1149-1156. (C) This work is licensed under Creative

\section{Your next submission with Juniper Publishers} will reach you the below assets

- Quality Editorial service

- Swift Peer Review

- Reprints availability

- E-prints Service

- Manuscript Podcast for convenient understanding

- Global attainment for your research

- Manuscript accessibility in different formats

( Pdf, E-pub, Full Text, Audio)

- Unceasing customer service

Track the below URL for one-step submission https://juniperpublishers.com/online-submission.php 